http://jmscr.igmpublication.org/home/ ISSN (e)-2347-176x ISSN (p) 2455-0450

crossref DOI: https://dx.doi.org/10.18535/jmscr/v8i11.88

Journal Of Medical Science And Clinical Research

\title{
Study of ECG Abnormalities in Acute Cerebro Vascular Accidents in a Tertiary Care Hospital of North Andhra Pradesh
}

\author{
Authors \\ Dr Kovilapu Harikrishna ${ }^{1}$, Dr S. Sreenivas ${ }^{2}$, Dr Dadala Subhash ${ }^{3}$, Dr P.Aneesh ${ }^{4}$ \\ ${ }^{1,3,4}$ Post Graduates, Department of General Medicine \\ ${ }^{2}$ Professor \& HoD, Department of General Medicine \\ King George Hospital, Visakhapatnam, Andhra Pradesh, India
}

\begin{abstract}
Background: Cardiac abnormalities were described with various CNS diseases including seizures, trauma, ischemic stroke, ICH and less commonly tumours, electroconvulsive therapy and meningitis.ECG abnormalities are common occurring, in 92 percent of patients with acute stroke.

Materials and Methods: This is an observational cross-sectional study done for eight months in the Department of General Medicine, King George Hospital, Visakhapatnam, from January 2020 to August 2020. A total of 100 patients with a diagnosis of acute cerebrovascular accident were included in this study.

Results: Out of the 100 patients, 54 were ischemic strokes, and 40 are intracerebral haemorrhage and 6 are subarachnoid hemorrhage. 38 out of 54 ischemic strokes showed ECG abnormalities, 34 out of 40 cases of intracerebral haemorrhage showed ECG abnormalities, all 6 cases of SAH showed ECG abnormalities.

Conclusion: ECG changes were more commonly associated with intracerebral haemorrhage compared with cerebral infarction.ST segment changes were the most common abnormality noted in our study. It was most commonly associated with ICH.

Keywords: ECG Abnormalities, Acute Cerebrovascular Accidents, Tertiary Care Hospital.
\end{abstract}

\section{Introduction}

Cushing first described hemodynamic changes after acute intracerebral hemorrhage. 1 Cardiac abnormalities were described with various CNS diseases including seizures, trauma, ischemic stroke, ICH and less commonly tumors, electroconvulsive therapy and meningitis. ${ }^{2}$

The anatomy and physiology of pathways involved in brain-heart interaction have been elucidated in both animal and human studies. The ability to reproduce the arrhythmia by activation of the sympathetic nervous system suggested a neurogenic mechanism. ${ }^{6,7}$

The medulla has been described as the principal site of vagal parasympathetic and sympathetic areas involved in cardiac control. Cardiac abnormalities occur in 60 to 70 percent of patients after stroke. 20 The most common disturbance includes ECG abnormalities, cardiac arrhythmias and myocardial injury and dysfunction 
distinguishing cardiac abnormalities directly caused by stroke. It however remains difficult because the prevalence of pre-existing cardiac disease is high particularly among patients with ischemic stroke. $^{21,22}$

An observational study of stroke patients indicated an increase incidence of sudden death among patients with right insular strokes. ${ }^{37}$ Right middle cerebral artery strokes were associated with increased incidence of supraventricular tachyarrhythmias. ECG abnormalities are common occurring, in 92 percent of patients with acute stroke. ${ }^{44}$ In 1947, Byer and colleagues first described marked QT prolongation with large $\mathrm{T}$ and $U$ waves on the ECG of four patients with stroke. $^{45}$ Subsequently Burch and colleagues described an ECG pattern after stroke consisting of large inverted Twaves, prolonged QT intervals and large septal $U$ waves that has become distinctive of cerebral vascular injury. ${ }^{45}$

\section{Aims and Objectives}

To study the incidence and pattern of ECG changes in patient with cerebrovascular accidents.

$>$ To study the association of ECG changes with electrolytes abnormalities

$>$ To assess the relation of ECG changes in acute cerebrovascular accident to the location of cerebral lesion.

\section{Materials and Methods}

Study Population: All patients admitted to medical ward with acute cerebrovascular accidents. The study was conducted at king
George Hospital during the year january2020 to august 2020 on all patients admitted to medical ward with acute cerebrovascular accidents. Study population consisted of 100 patients. This is an observational study

\section{Inclusion Criteria}

- All patients with acute cerebrovascular accidents.

\section{Exclusion Criteria}

Following patients were excluded from the study:

- Patients with underlying heart diseases.

- Patients on drugs.

- Previously diagnosed patients with electrolyte abnormalities.

- Patient with hepatic or renal diseases.

\section{Methodology}

All patients with acute cerebrovascular accidents were studied. They were assessed with serum electrolytes, $\mathrm{X}$ ray and blood urea and sugar 12 lead ECG was taken and monitored on the day of admission. CT scan was taken within 24-48 hrs. Screening ECHO was done on all patients with ECG changes. Patients showing cardiomegaly on $\mathrm{X}$ ray were excluded from the study. Patients previously diagnosed to have electrolyte abnormalities were also excluded from the study. Patients were categorized based on the CT finding as cerebral infarction, cerebral hemorrhage and sub- arachnoid hemorrhage. ECG was then interpreted with rate, rhythm, ST segment, QRS complex, T wave amplitude and morphology and QT interval was calculated. QTC interval was calculated based on Bazettsformulae.

\section{Results}

\begin{tabular}{|l|c|c|c|}
\hline Study Group & No of Cases & Abnormal Cases & Percentage \\
\hline Cerebral Infarction & 54 & 38 & 70 \\
\hline Cerebral Hemorrhage & 40 & 34 & 89 \\
\hline $\begin{array}{l}\text { Subarachnoid } \\
\text { Hemorrhage }\end{array}$ & 6 & 6 & 100 \\
\hline Total & 100 & 78 & 78 \\
\hline
\end{tabular}




\section{ABNORMAL ECG}

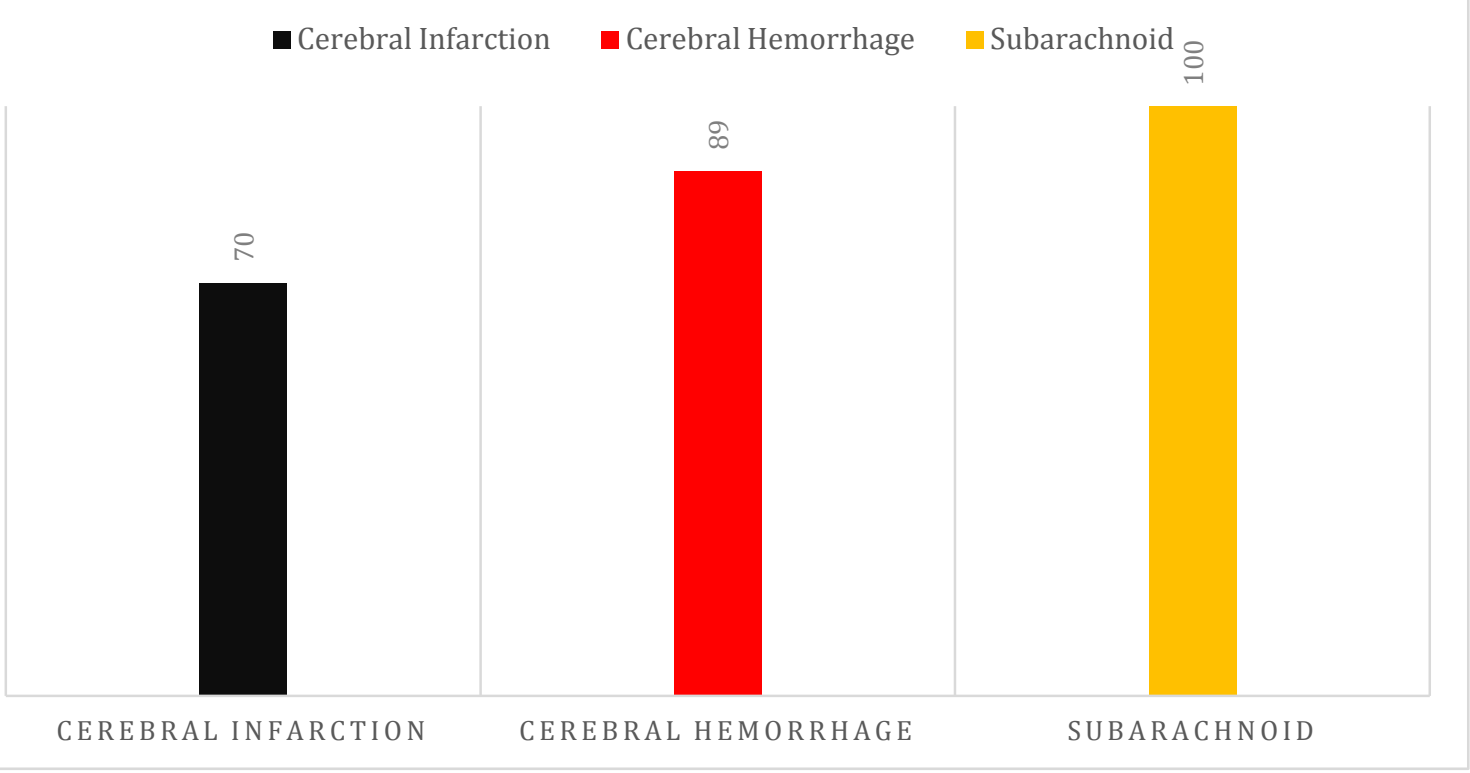

\begin{tabular}{|c|c|c|c|c|}
\hline Study group & $\begin{array}{c}\text { Total No } \\
\text { Cases }\end{array}$ & $\begin{array}{c}\text { ST } \\
\text { Segment } \\
\text { Elevation }\end{array}$ & $\begin{array}{c}\text { ST } \\
\text { Depression } \\
\text { Segment }\end{array}$ & $\begin{array}{c}\text { Percentage } \\
\text { With ST Segment } \\
\text { Changes }\end{array}$ \\
\hline Cerebral Infarction & 54 & $2(3 \%)$ & $18(33.3 \%)$ & $20(37 \%)$ \\
\hline $\begin{array}{c}\text { Cerebral } \\
\text { Hemorrhage }\end{array}$ & 40 & $20(50 \%)$ & $4(10 \%)$ & $24(60 \%)$ \\
\hline $\begin{array}{c}\text { Subarachnoid } \\
\text { Hemorrhage }\end{array}$ & 6 & $2(33.3 \%)$ & 0 & $2(33.3 \%)$ \\
\hline
\end{tabular}

\begin{tabular}{|c|c|c|c|}
\hline Study Group & Total No of Cases & Prolonged QTC & Percentage \\
\hline Cerebral Infarction & 54 & 16 & $29.6 \%$ \\
\hline Cerebral Hemorrhage & 40 & 20 & $50 \%$ \\
\hline Subarachnoid Hemorrhage & 6 & 2 & $33 \%$ \\
\hline
\end{tabular}

\begin{tabular}{|l|c|c|c|c|}
\hline Study Group & $\begin{array}{c}\text { Total No of } \\
\text { Cases }\end{array}$ & Tall T Waves & $\begin{array}{c}\text { T Wave } \\
\text { Inversion }\end{array}$ & $\begin{array}{c}\text { Percentage with T } \\
\text { Waves Changes }\end{array}$ \\
\hline Cerebral Infarction & 54 & $4(7 \%)$ & $12(22.2 \%)$ & $16(30 \%)$ \\
\hline $\begin{array}{l}\text { Cerebral Hemorrhage } \\
\text { Subarachnoid } \\
\text { Hemorrhage }\end{array}$ & 60 & $14(35 \%)$ & $4(10 \%)$ & $18(45 \%)$ \\
\hline
\end{tabular}

\section{Discussion}

The study was carried out in medicine ward. Study population consisted of 100 cases of which 54 cases were cerebral infarction and 40 cases were cerebral hemorrhage6 cases were SAH. For all these patients admitted to the medical ward base line RFT AND ELECTROLYTES were taken and analysed.

Patients with previous abnormalities were excluded from the study. 12 lead ECG taken for all the patients admitted and were monitored. ct scan was taken within 24-48 hrs and analysed and patients were categorized as cerebral infarct and intracerebral hemorrhage and SAH. In our study considerable no of patients had ECG changes.

The most common abnormality noted was ST segment changes in patient with cerebral hemorrhage. 60 percent of patients had the above changes. Of which $50 \%$ had st segment elevation and $10 \%$ had ST segment depression. This findings consistent with study of Frentz and Gorsmen who reported an incidence of $71 \%$ with 
ICH and $15 \%$ with infarction and also study of Lindgren Et Al who showed ST segment depression in lateral leads.

\section{Conclusion}

Of all the CVA patients assessed in this study, ECG changes of all forms were noted in as high as $78 \%$ of the patients. ECG changes were more commonly associated with intracerebral hemorrhage compared with cerebral infarction. ST segment changes were the most common abnormality noted in our study. It was most commonly associated with ICH. Next common abnormality noted was QTc prolongation which was noted in $50 \%$ of patient. Most common in patients with $\mathrm{ICH}$. T wave changes were noted in $45 \%$ of patients. Most commonly observed in patients with ICH. Tall T wave was noted mostly in ICH. Rhythm disturbance were noted in $40 \%$ percent of patients with ICH. Sinus bradycardia was the common abnormality associated with

ICH. 7\% percent of the patients with cerebral infarction had pathological Q waves.

\section{Limitations}

The study is done in a limited number of patients. Results may vary when done in a large number of subjects.

\section{Source of Support: None \\ Conflict of Interest: None}

\section{References}

1. Czaja CA, Scholes D, Hooton TM, Stamm WE: Population-based epidemiologic analysis of acute pyelonephritis. Clin Infect Dis. 2007, 45:273-280. 10. 1086/519268

2. Stone SC, Mallon WK, Childs JM, Docherty SD. Emphysematous pyelonephritis: clues to rapid diagnosis in the Emergency Department. J Emerg Med. 2005 Apr;28(3):315-9.
3. Umesha L, Shivaprasad SM, Rajiv EN, et al. Acute Pyelonephritis: A Single-center Experience. Indian J Nephrol. 2018;28 (6):454-461. doi:10.4103/ijn.IJN_219_16

4. Georgi Abraham, Yuvaram N.V. Reddy, Gautam George. Nephrology Dialysis Transplantation, Volume 27, Issue 9, September 2012, Pages 3391-3394.

5. Kumar S, Ramachandran R, Mete U, et al. Acute pyelonephritis in diabetes mellitus: single center experience. Indian J Nephrol. 2014;24:367-71

6. Patel HB, Soni ST, Bhagyalaxmi A, Patel NM. Causative agents of urinary tract infections and their antimicrobial susceptibility patterns at a referral center in Western India: An audit to help clinicians prevent antibiotic misuse. $J$ Family Med Prim Care. 2019;8(1):154159. doi:10.4103/jfmpc.jfmpc_203_18

7. KALYANAKRISHNAN RAMAKRISHNAN, M.D., and DEWEY C. SCHEID, M.D., M.P.H., University of Oklahoma Health Sciences Center, Oklahoma City, Oklahoma Am Fam Physician. 2005 Mar 1;71(5):933-942. 